\title{
Predictors for blood loss in pediatric patients younger than 10 years old undergoing primary posterior hemivertebra resection: a retrospective study
}

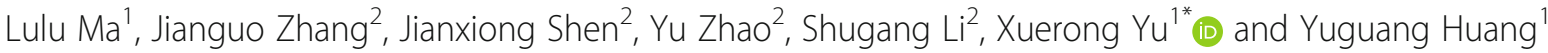

\begin{abstract}
Background: Blood loss during hemivertebra resection may be substantial. Few studies have examined the risk factors of blood loss undergoing hemivertebra resection, especially those in patients under 10 years old.

Methods: Patients under 10 years old diagnosed with congenital scoliosis and hemivertebra were retrospectively included from January 2014 to October 2017. They all had primary posterior hemivertebra resection at Peking Union Medical College Hospital. Perioperative information was collected and multivariable linear logistic regression was performed to determine the independent risk factors of blood loss.

Results: One hundred three patients were included. The mean total blood loss was $346+178 \mathrm{ml}$. The percentage of total blood loss to the EBV was $27.0+13.3 \%$. Multivariable linear logistic regression indicated that preoperative total Cobb angle $(P=0.046)$ and the number of fused levels $(P<0.001)$ were independent risk factors of total blood loss. Preoperative platelet count and preoperative coagulation function were not associated with blood loss in patients undergoing hemivertebra resection.

Conclusions: Preoperative total Cobb angle and the number of fused levels determined the blood loss for patients undergoing hemivertebra resection.
\end{abstract}

Keywords: Congenital scoliosis, Hemivertebra resection, Blood loss

\section{Background}

Hemivertebra is a common cause for congenital scoliosis. It has growth potential and can lead to spine deformity. Early detection and surgical intervention are recommended. Posterior resection of hemivertebrae with transpedicular instrumentation has been proven as a safe procedure for the correction of congenital scoliosis [1]. However, spine surgery is usually complex and associated with blood loss, placing patients at a high risk of allogeneic transfusion [2].

Allogenic transfusions have potential risks, including transfusion transmitted infection, fever, transfusion associated circulatory overload, immunologic and allergic

\footnotetext{
* Correspondence: yxr313@aliyun.com

${ }^{1}$ Department of Anesthesiology, Peking Union Medical College Hospital, Beijing 100730, China

Full list of author information is available at the end of the article
}

reactions. Transfusions are also associated with increased postoperative complications, length of hospital stay and 30-day readmission rate for patients undergoing elective spine surgery [3].

Several strategies have been used to reduce the need for transfusion in spine surgeries: normovolemic hemodilution, controlled hypotension and antifibrinolytics. However, these techniques do have risks and they can't eliminate the overall requirement for transfusion in spine surgeries. So it is necessary to understand which patients are at risk of massive blood loss for major spine surgery. Preoperative prediction of blood loss can help us make better preparation for potential bleeding, avoid unnecessary preoperative cross-match and waste of blood products.

However, there are few articles about blood management in patients with congenital scoliosis due to 
hemivertebrae, especially those under 10 years old. The aim of this study was to investigate the possible independent predictors of blood loss.

\section{Methods}

One hundred three consecutive patients diagnosed with congenital scoliosis and hemivertebra were included in the study. They had primary posterior hemivertebra resection and infusion at Peking Union Medical College Hospital from January 2014 to October 2017. Exclusion criteria included prior spine operation, patients who had two hemivertebra resected and known bleeding problems.

Medical records of these patients were reviewed. All patients were induced with propofol $(3 \mathrm{mg} / \mathrm{kg})$, fentanyl $(2 \mu \mathrm{g} / \mathrm{kg})$ and rocuronium $(0.6 \mathrm{mg} / \mathrm{kg})$. General anesthesia was maintained with continuous infusion of propofol and remifentanil. Fentanyl boluses $(1-2 \mu \mathrm{g} / \mathrm{kg})$ were given when necessary for intraoperative analgesia. Blood pressure was maintained without decreasing lower than $20 \%$ of the preanesthetic value measured before induction of anesthesia. Ringers Lactate was used for fluid maintenance and colloid or blood products were administered when necessary. Tranexamic acid was not used. Intraoperative blood salvage with the bowl set of $70 \mathrm{ml}$ (Haemonetics Cell Saver 5+, Haemonetics Corporation, Braintree, MA, USA) was used depending on the estimation of significant bleeding by surgeons.

All patients had posterior hemivertebra resection and bilateral transpedicular instrumentation in prone position. Intraoperative transcranial motor evoked potential (MEP) were used. For lumbar hemivertebra, one upper and one lower vertebra were fused. For thoracic hemivertebra, two upper and two lower vertebra were fused. In some instances, fused levels were extended to three or more upper and/or lower vertebra in case of severe scoliotic or kyphotic deformity. The posterior elements of hemivertebra, including the lamina, upper and lower facets and transverse process were removed. The rib head and the proximal part of the surplus rib on the convex side were also removed in patients with thoracic hemivertebra. Before the resection of vertebra body, a temporary rod was connected to screws on the concave side. The upper and lower discs, including the cartilage endplate were removed completely. The contra-lateral cartilage tissue of the hemivertebra was also resected. For patients with contralateral bar and rib synostosis, resection of bar and the synostosed rib heads was necessary. For patients with large hemivertebra or obvious kyphosis, a mesh cage filled autologous bone graft was needed to provide postoperative stability. Before closing, the drainage tube was placed underneath paravertebral muscles and disposable drainage bag was emptied every $24 \mathrm{~h}$ after the measurement of drainage volume. After operation, all patients were weaned from ventilator and extubated with the resume of adequate spontaneous ventilation and airway reflexes, minimal secretions and hemodynamic stability.

Patients' information including age, sex, height, weight, past medical history, preoperative and postoperative segmental and total Cobb angles, segmental kyphosis or lordosis, fusion levels, operation time, estimated blood loss, intraoperative infusion of fluid, postoperative wound drainage and complications were collected. Cobb angles were measured according to the description by Ruf [1] Segmental Cobb angle was measured from the upper endplate of the vertebra above the hemivertebra to the lower endplate of the vertebra below the hemivertebra. Total Cobb angle was measured from the upper endplate of the most tilted vertebra on top of the curve and the lower endplate of the most tilted vertebra on the bottom of the cure. Segmental kyphosis/lordosis was measured from the upper endplate above the hemivertebra to the lower endplate below the hemivertebra on the coronal plane (Fig. 1).

Laboratory tests which included blood cell count and coagulant function were also recorded. Total blood loss was calculated as the sum of intraoperative and postoperative blood loss. Intraoperative blood loss included the amount of blood in suction container and soaked sponge. And postoperative blood loss was estimated as the volume of wound drainage within $48 \mathrm{~h}$ after operation. The EBV was calculated as followings: body weight $(\mathrm{kg}) * 75 \mathrm{ml} / \mathrm{kg}$ for patients $\leq 6$ years old and body weight $(\mathrm{kg}) * 70 \mathrm{ml} / \mathrm{kg}$ for patients $>6$ years old $[4,5]$. The percentage of total blood loss to EBV was used for the evaluation of blood loss.

Standardized statistical software (SPSS19, CHICAGO, IL) was used for statistical analysis. Data were reported as mean \pm standard deviation (SD) for normally distributed variables or median [25th, 75th interquartile range] for others. Potential predictor variables were first evaluated by calculating Pearson correlation coefficients, and multivariable linear logistic regression was performed to determine the independent risk factors of blood loss. $P<0.05$ was defined as significant.

\section{Results}

One hundred three consecutive patients, consisting of 45 girls and 58 boys were included in the study. The demographic characteristics and preoperative data were summarized in Table 1. Median age was $3[2,6]$ years old. The mean preoperative segmental and total Cobb angle and segmental kyphosis/lordosis were $40^{\circ} \pm 12^{\circ}, 35^{\circ} \pm 12^{\circ}$ and $20^{\circ} \pm 15^{\circ}$ respectively. Figure 2 showed preoperative and postoperative radiographs of two patients. .

The intraoperative and postoperative data were summarized in Table 2. The correction of segmental and total Cobb angle and segmental kyphosis/lordosis were 

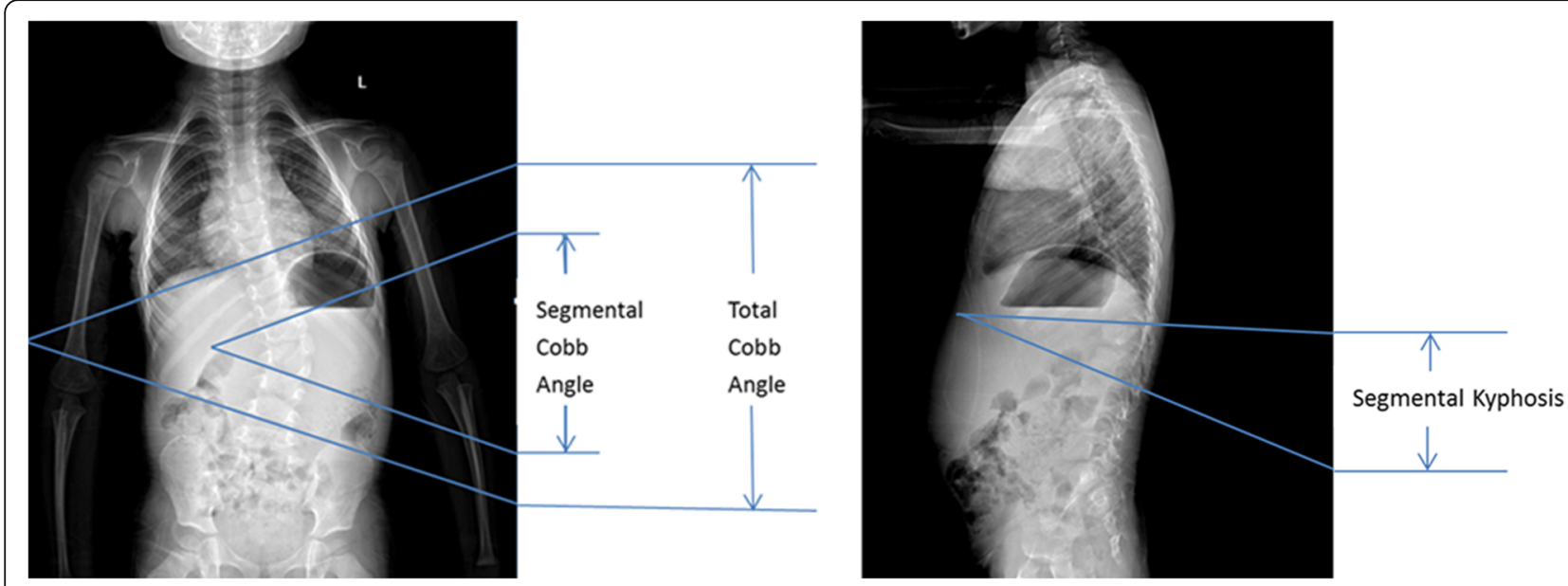

Fig. 1 Angles measured in the anterior-posterior and lateral view: Segmental Cobb angle, total Cobb angle and segmental kyphosis

$72.6 \% \pm 21.7 \%, 65.6 \pm 21.9$ and $45.2 \pm 53.5 \%$ respectively. The mean average operation time was $176+40$ min. The mean intraoperative blood loss, postoperative drainage volume and total blood loss were $225 \pm 142 \mathrm{ml}$, $121 \pm 78 \mathrm{ml}$ and $346 \pm 178 \mathrm{ml}$ respectively. The percentage of total blood loss to the EBV was $27.0 \pm 13.3 \%$. $41(39.8 \%)$ patients used cell saver intraoperatively, and the overall allogenic transfusion rate was $73.8 \%$.

Four cases of delayed wound healing and one case of numbness of lower extremities occurred. One patient had revision surgery due to displacement of internal

Table 1 Demographic characteristics and preoperative data of patients $(n=103)$. Data were presented as mean \pm SD, median [25th, 75th interquartile range] or number (percentage)

\begin{tabular}{|c|c|}
\hline Variables $^{a}$ & \\
\hline \multicolumn{2}{|l|}{ Sex } \\
\hline Female & $45(43.7 \%)$ \\
\hline Male & $58(56.3 \%)$ \\
\hline Age(yr) & $3[2,6]$ \\
\hline Height(cm) & $96[90,115]$ \\
\hline Weight(Kg) & $15.0[13,22]$ \\
\hline BMl & $16.6 \pm 2.1$ \\
\hline Segmental Cobb angle( $\left(^{\circ}\right)$ & $40 \pm 12$ \\
\hline Total Cobb angle $\left(^{\circ}\right)$ & $35 \pm 12$ \\
\hline Segmental kyphosis $\left({ }^{\circ}\right)$ & $20 \pm 15$ \\
\hline Preoperative Hemoglobin(g/l) & $130 \pm 11$ \\
\hline Preoperative platelet count $\left({ }^{\mathrm{a}} 109\right)$ & $305 \pm 66$ \\
\hline Preoperative PT(s) & $12.0 \pm 0.7$ \\
\hline Preoperative APTT(s) & $32.6 \pm 3.8$ \\
\hline Preoperative fibrinogen(g/l) & $2.3 \pm 0.5$ \\
\hline
\end{tabular}

${ }^{a}$ Mean + SD for normal distribution; median [25th,75th interquartile range] for others fixation. There was no mortality and no complication related to blood loss or allogenic transfusion.

Multivariable linear logistic regression indicated that total Cobb angle $(P=0.046)$ and the number of fused levels $(P<0.001)$ were independent risk factors of total blood loss. (See Table 3).

\section{Discussion}

Blood loss with hemivertebrae resection is variable due to intraoperative exposure of paraspinal muscles, vertebral bodies and associated venous plexus. For pediatric patients younger than 10 years old, blood loss is very important because of lower weight, smaller blood volume and more sensitive to fluid loss or overdose when compared to adolescent or adult patients. There have been few reports on blood management in pediatric patients undergoing posterior resection of hemivertebra, especially in patients under 10 years old. Our study demonstrated that for patients undergoing primary posterior hemivertebra resection, perioperative blood loss was predicted by preoperative total Cobb angel and the number of fused levels.

In our study, blood loss was assessed by both intraoperative blood loss and postoperative drainage, while most previous studies focused on only intraoperative blood loss [6-8]. However bleeding usually lasts until the postoperative period for spine deformity surgeries [9]. And in our study, postoperative drainage counted for $35.6 \%$ (data not listed) of total blood loss, which also suggested the necessity of including postoperative drainage when assessing total blood loss. Both hemoglobin [10] and the need for blood transfusion [11] had been used to evaluate perioperative bleeding in hemivertebra resection. However, intravenous fluid intake can influence the value of hemoglobin and the criteria of transfusion at different hospitals and countries are variable, 

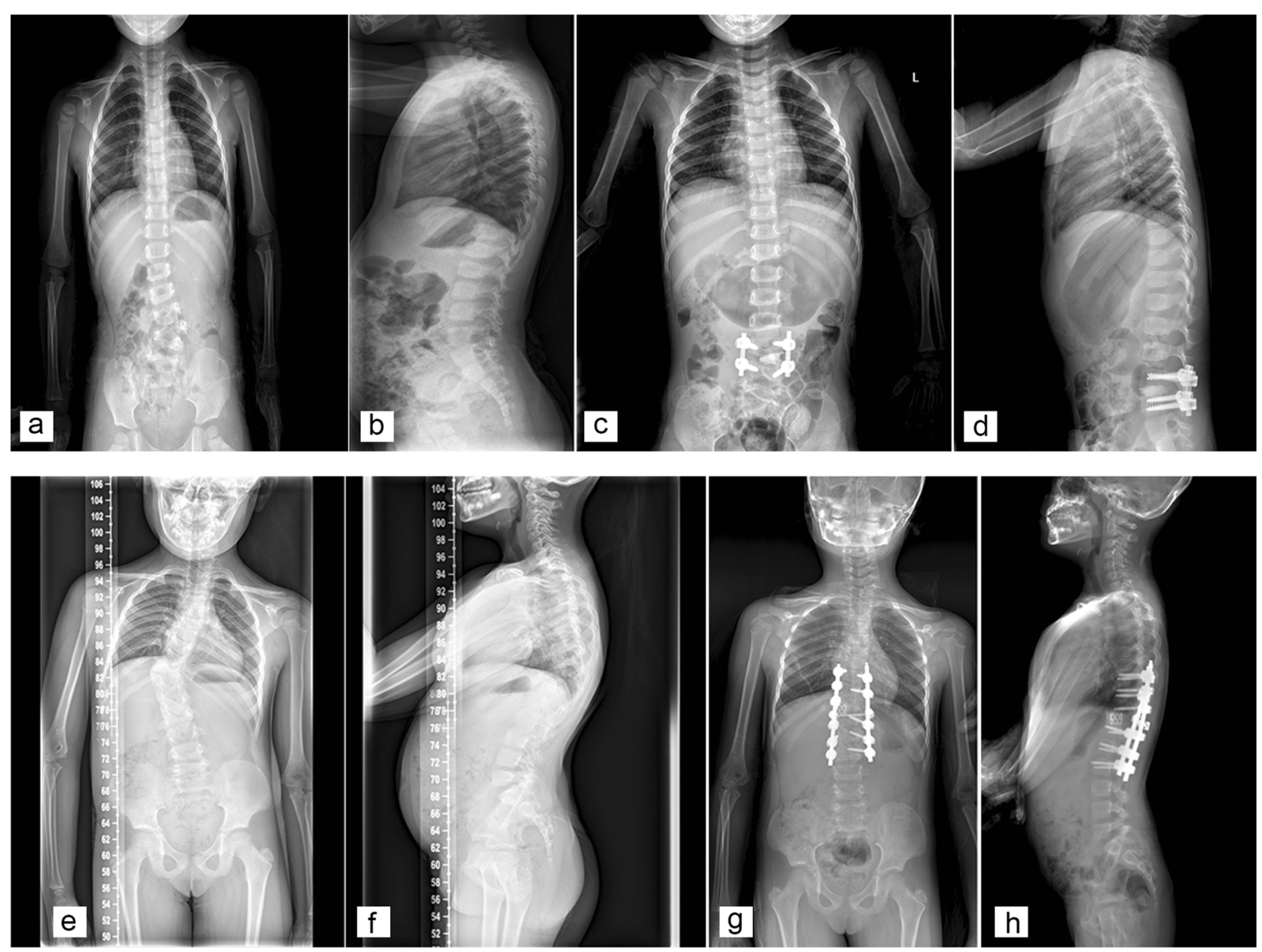

Fig. 2 Preoperative and postoperative radiographs of two patients. $\mathbf{a}, \mathbf{b}, \mathbf{c}, \mathbf{d}$ :a 2-year-old girl with a fully segmented hemivertebra at L4/5. e, f, $\mathbf{g}$ h:a 7-year-old girl with a hemivertebra at T11

Table 2 Intra-operative and post-operative data of patients $(n=103)$

\begin{tabular}{ll}
\hline Variables $^{*}$ & \\
\hline Correction of segmental Cobb angle(\%) & $72.6 \pm 21.7$ \\
Correction of total Cobb angle(\%) & $65.6 \pm 21.9$ \\
Correction of segmental kyphosis/lordosis(\%) & $45.2 \pm 53.5$ \\
The number of fused levels & $3[2,5]$ \\
Resection of ribs (n(\%)) & $11(10.7 \%)$ \\
Length of surgery(minute) & $176 \pm 40$ \\
Intraoperative blood loss(ml) & $225 \pm 142$ \\
Postoperative drainage(ml) & $121 \pm 78$ \\
Total blood loss(ml) & $346 \pm 178$ \\
percentage of total blood loss to the EBV & $27.0 \pm 13.3$ \\
Intraoperative cell saver use (n/\%) & $41(39.8 \%)$ \\
Intraoperative crystalloid (ml) & $500[300,700]$ \\
Intraoperative colloid(ml) & $0[0,100]$ \\
Allogenic transfusion(n(\%)) & $76(73.8 \%)$ \\
\hline
\end{tabular}

making them unreliable. Instead of the absolute value of total blood loss [12], we used the percentage of total blood loss to EBV for the evaluation of blood loss, which was more accurate by taking patients' size into account. It is more reasonable to use the percentage when comparing blood loss of different studies and it is more valuable in determining transfusion. The ratio of total blood loss to EBV was $27.0 \%$ in our study, which was in accordance with previous report [12].

Previous studies have identified factors associated with increased blood loss in scoliosis, which include larger Cobb angles [9, 13], the number of segments fused [14] and osteotomy [13]. For patients undergoing one hemivertebra resection, the independent risk factors for blood loss are the preoperative total Cobb angel and the number of fused levels. Both reflect the severity of scoliosis. And the more levels are fused, the more muscle and vertebra are exposed.

Transfusion rate was $73.8 \%$ in our case series. The reasons of high transfusion rate were as the followings: First, 
Table 3 Univariable and multivariable linear regression models for blood loss

\begin{tabular}{|c|c|c|c|c|}
\hline \multirow[t]{2}{*}{ Predictor variable } & \multicolumn{2}{|c|}{ Univariable } & \multicolumn{2}{|l|}{ Multivariable } \\
\hline & Pearson & $P$ value & $\mathrm{B}(95 \% \mathrm{Cl})$ & $P$ value \\
\hline Sex & 0.026 & 0.793 & & \\
\hline Age & -0.043 & 0.663 & & \\
\hline Height(cm) & -0.079 & 0.425 & & \\
\hline Weight(Kg) & -0.133 & 0.182 & & \\
\hline BMl & -0.146 & 0.141 & & \\
\hline Segmental Cobb angle $\left(^{\circ}\right)$ & 0.373 & $<0.001^{*}$ & $0.001(-0.002-0.003)$ & 0.596 \\
\hline Total Cobb angle $\left(^{\circ}\right)$ & 0.474 & $<0.001^{*}$ & $0.003(0.000-0.005]$ & $0.046^{*}$ \\
\hline Segmental kyphosis $\left({ }^{\circ}\right)$ & 0.085 & 0.396 & & \\
\hline Correction of segmental Cobb angle(\%) & 0.022 & 0.829 & & \\
\hline Correction of total Cobb angle(\%) & -0.081 & 0.417 & & \\
\hline Correction of segmental kyphosis/lordosis(\%) & -0.084 & 0.400 & & \\
\hline The number of fused levels & 0.535 & $<0.001^{*}$ & $0.036(0.0147-0.054)$ & $<0.001^{*}$ \\
\hline Resection of ribs $(n(\%))$ & 0.140 & 0.159 & & \\
\hline Length of surgery(minute) & 0.333 & $0.001^{*}$ & $-1.262 \mathrm{E}-5(-0.001-0.001)$ & 0.970 \\
\hline Preoperative Hemoglobin(g/l) & 0.010 & 0.921 & & \\
\hline Preoperative platelet count $\left({ }^{*} 109\right)$ & -0.049 & 0.623 & & \\
\hline Preoperative PT(s) & 0.067 & 0.503 & & \\
\hline Preoperative APTT(s) & -0.053 & 0.594 & & \\
\hline Preoperative fibrinogen(g/l) & -0.057 & 0.570 & & \\
\hline
\end{tabular}

$\left({ }^{*} P<0.05\right)$

all patients had osteomy. Osteomy had been confirmed as the risk factor of blood loss and transfusion in adolescent idiopathic scoliosis patients [13]. Secondly, intraoperative monitoring is essential for spine surgery, and transcranial motor evoked potential (MEP) was used in our series to prevent spinal cord injury. However, due to the immaturity of motor nervous pathways in young children, the successful rate of baseline of MEP was lower, and the waveform and amplitude were poor when compared to those in adolescent patients [15]. Hypotension and anemia due to hemorrhage may also lead to MEP deterioration. Expanding intravascular volume and restoring hemoglobin level (9-10 $\mathrm{g} / \mathrm{dl}$ ) are necessary [16]. Tranexamic acid was not used in our case series. Although tranexamic acid has been confirmed to decrease blood loss in adolescent idiopathic scoliosis [17] and pediatric vertebral column resection [18], its safety and dosage guidelines among children, especially those under 10 years old are unknown.

Preoperative platelet count and coagulation function were not related to blood loss in our study. Decreased platelet quantity was detected in patients during spine surgeries [19], however thrombocytopenia had limited effect on bleeding in patients with idiopathic scoliosis undergoing spine deformity surgeries [20]. Hypercoagulable state followed by fibrinolysis [21] was reported in patients after spinal surgeries. Besides these, preoperative fibrinogen concentration was proven to be associated with perioperative bleeding and transfusion [11]. We didn't find the relationship between preoperative fibrinogen level and bleeding in our study. And the role of coagulation mechanism in the bleeding of hemivertebra resection remains unclear.

There are several limitations in our study. First, this is a retrospective study with limited number of patients. Second, it was a single-center study and the validity of our results was limited.

\section{Conclusions}

In conclusion, preoperative total Cobb angle and the number of fused levels are the predictor for blood loss for patients undergoing one hemivertebra resection surgery. Further researches are necessary to determine the role of blood management in decreasing blood loss and transfusion in patients undergoing hemivertebra resection.

\section{Abbreviations \\ APTT: Activate partial thromboplastin time; EBV: Estimated blood volume: INR: International normalized ration:; MEP: Motor evoked potential; PT: Prothrombin time; SD: Standard deviation}

Acknowledgements

The authors thank Haiyu Pang and Yuelun Zhang for their help in statistics.

Authors' contributions

LM made contributed to acquisition of data, interpretation of results and manuscript preparation. XY performed statistical analysis. JZ, JS, YZ, SL and YH made contributions to the conception of this study. JZ, JS, YZ and SL performed the operation and provided data for this manuscript. YH contributed to the study 
coordination and made revision of this manuscript. All authors read and approved the final manuscript

\section{Funding}

This study was supported by the CAMS Innovation Fund for Medical Sciences (CIFMS) (2016-12 M-3-024).

\section{Availability of data and materials}

The datasets used and/or analysed during the current study are available from the corresponding author on reasonable request.

\section{Ethics approval and consent to participate}

This retrospective study was approved by the Ethic Committee of Peking Union Medical College Hospital and written informed consent was not required for retrospective studies.

\section{Consent for publication}

Consent for publication of radiograph had been obtained from their parents.

\section{Competing interests}

The authors declare that they have no competing interests.

\section{Author details}

'Department of Anesthesiology, Peking Union Medical College Hospital, Beijing 100730, China. ${ }^{2}$ Department of Orthopedics, Peking Union Medical College Hospital, Beijing 100730, China.

Received: 19 July 2018 Accepted: 11 June 2019

Published online: 22 June 2019

\section{References}

1. Ruf M, Harms J. Hemivertebra resection by a posterior approach: innovative operative technique and first results. Spine. 2002;27(10):1116-23.

2. Bowen RE, Gardner S, Scaduto AA, Eagan M, Beckstead J. Efficacy of intraoperative cell salvage systems in pediatric idiopathic scoliosis patients undergoing posterior spinal fusion with segmental spinal instrumentation. Spine. 2010;35(2):246-51.

3. Elsamadicy AA, Adogwa O, Vuong VD, Mehta Al, Vasquez RA, Cheng J, et al. Association of Intraoperative Blood Transfusions on postoperative complications, 30-day readmission rates, and 1-year patient-reported outcomes. Spine. 2017;42(8):610-5.

4. Zuo Y, Zhu B, Zhuang L, Lian Q, Xiao W, Song X, et al. Perioperative management of pediatric fluid and blood management. Beijing: Peolple's medical publishing house; 2017. p. 278-83.

5. Goobie SM, Haas T. Bleeding management for pediatric craniotomies and craniofacial surgery. Pediatr Anesth. 2014:24:678-89.

6. Nuttall GA, Horlocker TT, Santrach PJ, Oliver WC Jr, Dekutoski MB, Bryant S. Predictors of blood transfusions in spinal instrumentation and fusion surgery. Spine. 2000;25:596-601.

7. Zheng F, Cammisa FP Jr, Sandhu HS, Girardi FP, Khan SN. Factors predicting hospital stay, operative time, blood loss, and transfusion in patients undergoing revision posterior lumbar spine decompression, fusion, and segmental instrumentation. Spine. 2002;27(8):818-24.

8. Suk SI, Kim JH, Kim WJ, Lee SM, Chung ER, Nah KH. Posterior vertebral column resection for severe spinal deformities. Spine. 2002;27(21):2374-82

9. Hassan N, Halanski M, Wincek J, Reischman D, Sanfilippo D, Rajasekaran S, et al. Blood management in pediatric spinal deformity surgery: review of a $2-$ year experience. Transfusion. 2011;51(10):2133-41.

10. Bollini $G$, Docquier $P L$, Viehweger $E$, Launay $F$, Jouve JL. Lumbar hemivertebra resection. J Bone Joint Surg Am. 2006;88(5):1043-52.

11. Mladenov K, Kunkel $P$, Stuecker R. Hemivertebra resection in children, results after single posterior approach and after combined anterior and posterior approach: a comparative study. Eur Spine J. 2012;21(3):506-13.

12. Carling MS, Jeppsson A, Wessberg P, Henriksson A, Baghaei F, Brisby H. Preoperative fibrinogen plasma concentration is associated with perioperative bleeding and transfusion requirements in scoliosis surgery. Spine. 2011;36(7):549-55.

13. Xuerong $Y$, Han $X$, Ruiying $W$, Huang $Y$. Prediction of massive blood loss in scoliosis surgery from preoperative variables. Spine. 2013;38(4):350-5.
14. Doi T, Harimaya K, Matsumoto $Y$, Taniguchi $H$, Iwamoto $Y$. Perioperative blood loss and extent of fused vertebrae in surgery for adolescent idiopathic scoliosis. Fukuoka Igaku Zasshi. 2011;102(1):8-13.

15. Wang S, Zhang J, Tian Y, Shen J. Rare true-positive outcome of spinal cords monitoring in patients under age 4 years. Spine J. 2016;16(9):1090-4.

16. Lieberman JA, Feiner J, Rollins M, Lyon R. Changes in transcranial motor evoked potentials during hemorrhage are associated with increased serum propofol concentrations. J Clin Monit Comput. 2017. https://doi.org/10. 1007/s10877-017-0057-4.

17. Lykissas MG, Crawford AH, Chan G, Aronson LA, Al-Sayyad MJ. The effect of tranexamic acid in blood loss and transfusion volume in adolescent idiopathic scoliosis surgery: a single-surgeon experience. J Child Orthop. 2013:7(3):245-9.

18. Newton PO, Bastrom TP, Emans JB, Shah SA, Shufflebarger HL, Sponseller $P D$, et al. Antifibrinolytic agents reduce blood loss during pediatric vertebral column resection procedures. Spine. 2012;37(23):e1459-63.

19. Sabato S, Rotman A, Robin GC, Floman Y. Platelet aggregation abnormalities in idiopathic scoliosis. J Pediatr Orthop. 1985;5(5):558-63.

20. Murray DJ, Pennell BJ, Weinstein SL, Olson JD. Packed red cells in acute blood loss: dilutional coagulopathy as a cause of surgical bleeding. Anesth Analg. 1995;80(2):336-42.

21. Bosch P, Kenkre TS, Londino JA, Cassara A, Yang C, Waters JH. Coagulation profile of patients with adolescent idiopathic scoliosis undergoing posterior spinal fusion. J Bone Joint Surg Am. 2016;98(20):e88.

\section{Publisher's Note}

Springer Nature remains neutral with regard to jurisdictional claims in published maps and institutional affiliations.
Ready to submit your research? Choose BMC and benefit from:

- fast, convenient online submission

- thorough peer review by experienced researchers in your field

- rapid publication on acceptance

- support for research data, including large and complex data types

- gold Open Access which fosters wider collaboration and increased citations

- maximum visibility for your research: over $100 \mathrm{M}$ website views per year

At BMC, research is always in progress.

Learn more biomedcentral.com/submissions 